\title{
Denegación interesada de justicia y prescripción de la acción penal
}

\author{
DENIAL OF JUSTICE AND STATUTE OF LIMITATIONS IN CRIMINAL LAW
}

JAVIER WILENMANN VON BERNATH*

\section{RESUMEN}

El artículo tematiza el problema jurídico vinculado a la aplicabilidad de la prescripción de la acción penal en situaciones de denegación interesada de justicia. El artículo muestra que, en la jurisprudencia actual de la Corte Interamericana de Derechos Humanos y de la Corte Suprema, se dispone el desconocimiento de los efectos de la prescripción en casos de denegación interesada de justicia con efecto sistemático. A partir de ello, el artículo presenta una interpretación de las reglas de prescripción que formaliza esta disposición: en aquellas situaciones en que se formaliza y acepta una denuncia por denegación de justicia ante los organismos del sistema interamericano, debe considerarse suspendido el transcurso de la prescripción de la acción penal.

\section{PALABRAS CLAVE}

Prescripción, denegación de justicia, justicia transicional.

\section{ABSTRACT}

The article analyses the application of statute of limitation defenses in cases of denial of justice. It posits that case law emanating from both the Interamerican Court of Human Rights and the Chilean Supreme Court requires statute of limitations defenses not to be applied in cases of denial of justice with a systematic origin. The article presents an interpretation of Chilean criminal law that provides for this effect.

\section{KEYWORDS}

Statute of limitations, denial of justice, transitional justice

\section{Introducción}

¿Cómo debe reaccionar el sistema de justicia frente a situaciones en que las reglas del sistema parecen formalizar un efecto de impunidad vinculado al control de facto del propio aparato estatal?

Situaciones de esta clase son conocidas tanto en contextos estatales anómalos (dictaduras) como en situaciones que calzan con una situación política normal.

En contextos anómalos, el autofavorecimiento del régimen puede operar tanto por manipulación de la licitud de las acciones como del aparato y las condiciones de persecución penal. Así, el régimen puede disponer, por ejemplo, la amnistía de todos los crímenes

\footnotetext{
* Profesor asociado y director de investigación Facultad de Derecho, Universidad Adolfo Ibáñez, Santiago, Chile. Correo electrónico: javier.wilenmann@uai.cl. El artículo se originó en un informe en derecho solicitado por el Ministerio Público en la causa de Alex Lemún. Su contenido no coincide, sin embargo, con el informe en cuestión, el que se centraba en cuestiones particulares vinculadas al caso.
} 
perpetrados durante un período especialmente intenso de represión brutal. Pero también puede disponer que ciertos modos de acción especialmente favorecidos por él se vean favorecidos por una causa de justificación. Más sencillamente, el régimen puede permanecer suficiente tiempo en el poder para que transcurra el plazo de prescripción de la acción penal de los delitos perpetrados durante un período determinado. En contextos de transición a la democracia, no es inusual que los arreglos políticos imperantes supongan la no-persecución por un tiempo suficiente para que ese plazo transcurra.

Aunque, como veremos, el derecho chileno se ha hecho cargo sobre todo de situaciones de esta clase, los problemas vinculados al autofavorecimiento de los propios agentes que controlan los aparatos de persecución penal también se han dado en contextos no dictatoriales. En contextos transicionales, las policías, el ejército o el poder judicial pueden mantener formas de acción que tienden a la perpetración de delitos y, a su vez, actitudes que permiten la impunidad de facto de sus propios funcionarios. En Chile y Latinoamérica, problemas de esta clase han estado ante todo vinculados a los estatutos de justicia militar - extensibles en ocasiones a las actuaciones de la policía-, los que sujetaban el conocimiento de todos los asuntos que involucraran a un militar al conocimiento de tribunales especiales. En esos contextos, es probable que se produzcan situaciones más o menos burdas de denegación interesada de justicia.

A diferencia de los contextos dictatoriales, en casos de esta especie el control del Estado no es total, por lo que la impunidad no tiende a producirse por manipulación de la licitud de las acciones. Antes, la denegación interesada de justicia tiene que operar por mecanismos procesales que hagan imposible la persecución penal, terminando con la extinción de la responsabilidad penal por prescripción o por reconocimiento de efecto de cosa juzgada. ¿Cómo debe reaccionar el sistema judicial frente a situaciones de esta clase?

El presente artículo tematiza esta pregunta, concentrándose en el problema del transcurso aparente del plazo de prescripción por causa de autofavorecimiento del aparato estatal. En términos gruesos, el artículo muestra que la jurisprudencia tanto nacional como interamericana reconocen que el efecto de la prescripción no tiene lugar respecto de ciertas situaciones de denegación interesada de justicia. Más precisamente, el artículo explica que ese efecto se produce en todas aquellas situaciones en que el origen de la denegación está sistemáticamente condicionado - sea que ello tuvo lugar en un contexto dictatorial o democrático. Por último, el artículo explica el razonamiento jurídico preciso que lleva al reconocimiento de ese efecto en el derecho chileno: en casos de esta clase, la jurisprudencia de derechos humanos obliga a reducir teleológicamente el alcance del artículo 96 del Código Penal (CP).

Para estos efectos, el artículo empieza dando cuenta de los antecedentes interpretativos que conduce al reconocimiento de este efecto (I). Tras explicar brevemente los usos lingüísticos centrales del artículo - denegación interesada de justicia, condicionamiento sistemático -, el artículo da cuenta de los antecedentes comparados, internacionales y domésticos que conducen a la conclusión, así como a las condiciones en que, de acuerdo a la jurisprudencia aplicable, se debe reconocer el efecto en cuestión. La segunda sección (II), por su parte, analiza la pregunta interpretativa respecto al modo preciso en que se produce el desconocimiento del efecto de la prescripción.

\section{La denegación interesada de justicia en el derecho comparado, internacional de los derechos humanos y en la jurisprudencia de la Corte Suprema}

Esta primera sección tiene por objeto explicar el razonamiento y las fuentes que se encuentran en el origen del desconocimiento de posibles defensas de prescripción y otras similares. Aquí nos interesa solo dar cuenta del resultado que tiende a ser reconocido y de las condiciones en que se reconoce ese resultado: desconocer el efecto de la prescripción. No nos 
interesa, en cambio, el problema preciso de las reglas que deben ser aplicadas o no aplicadas para llegar a este resultado. Ese es el objeto, en cambio, de la sección II.

Para estos efectos, empezaré por explicar los usos conceptuales más relevantes referidos al problema que nos ocupa (1). A continuación (2), daré cuenta del antecedente más conocido de derecho comparado de reconocimiento de un efecto de esta clase: la jurisprudencia alemana posterior a la Segunda Guerra Mundial y a la reunificación. Aunque no se trata de antecedentes vinculantes, se trata de un desarrollo ilustrativo de los problemas y modos de reacción frente a situaciones de denegación interesada de justicia. Finalmente $(3$ y 4$)$ daré cuenta de antecedentes que sí son directamente relevantes para el problema en cuestión en Latinoamérica y en Chile, especificando las condiciones que en las líneas jurisprudenciales en cuestión llevan a disponer el desconocimiento del efecto de la prescripción.

\subsection{El concepto de denegación interesada de justicia}

Por denegación interesada de justicia designo las situaciones en las que solicitud de intervención jurisdiccional es denegada por consideraciones que atañen, en general, al propio aparato estatal competente. Pese a que en el contexto del derecho internacional de los derechos humanos el concepto de "impunidad" juega a veces el mismo rol, se trata de una categoría más precisa y estrecha que esta. Impunidad describe simplemente un resultado - falta de punición debida -, sin calificar las razones por las que ello tiene lugar. Por cierto, en su uso relevante, el concepto de impunidad apunta precisamente a casos de favorecimiento interesado por sujetos de quienes se espera imparcialidad. Pero justamente para denotar que la referencia es solo a "impunidades" determinadas de ese modo y no, en cambio, a todo caso de ausencia de castigo, es que prefiero hacer uso del concepto de "denegación interesada de justicia". La denegación interesada de justicia es, en ese sentido, una omisión en la realización de actos jurisdiccionales condicionada por falta de imparcialidad de los organismos competentes en la persecución.

En general, la denegación interesada de justicia puede tener dos clases de origen: un origen sistemático-institucional o un origen contingente y particular.

El origen de la pérdida de imparcialidad es sistemático-institucional cuando por razones de configuración general del poder del Estado o por diseño institucional se encuentra comprometida el tipo de imparcialidad que se espera en relación con los actos que deben ser juzgados ${ }^{1}$.

Un ejemplo obvio de denegación interesada de justicia sistemáticamente condicionada se produce en el contexto de la persecución de crímenes de Estado cuando los tribunales, en los hechos, han perdido imparcialidad en relación al juicio de las acciones de agentes del Estado. Este es un fenómeno que tiende a darse en contextos dictatoriales y que ciertamente también tuvo lugar en Chile. Que en todos estos casos no son aplicables reglas de exclusión de responsabilidad penal cuya aplicación fue posibilitada por el régimen en el que se realizaban los crímenes, es algo largamente establecido por la Corte Interamericana de Derechos Humanos².

Pero el origen sistemático de la denegación interesada de justicia no necesita vincularse a contextos de deformación general del poder estatal. También el diseño institucional en un Estado que funciona al menos parcialmente como democracia (en una "democracia transicional") puede tender a denegación sistemáticas, siempre que el juicio de una clase de actos sea dejado a instituciones de las cuales no pueda esperarse imparcialidad frente al tipo de actos que deben juzgar. En Chile y en Latinoamérica, como veremos, el caso más relevante de diseño de esta clase ha estado vinculado a la sujeción a jurisdicción militar a los delitos comunes contra particulares cometidos por militares y policías en distintos ordenamientos

\footnotetext{
${ }^{1}$ Por supuesto, no es poco común que ambos aspectos vayan de la mano: que delitos cometidos en un contexto original de protección frente a la persecución sean luego sujetos a un régimen institucional que no tiene imparcialidad para juzgarlos. Ese es el caso de la judicatura militar en relación a delitos cometidos por sus funcionarios antes y después de la dictadura y un aspecto central del caso Almonacid. Véase al respecto GUZMÁN (2013), pp. 155 y ss.

2 Véase nota 13.
} 
latinoamericanos, algo que ha sido largamente establecido por la Corte Interamericana de Derechos Humanos ${ }^{3}$. Nada excluye, a su vez, que el aparato estatal se corrompa de modo tal que pierda por completo imparcialidad frente a sus propios agentes, con lo que el origen sistemático no necesita originarse en cuestiones de diseño institucional.

En cambio, la denegación interesada de justicia es puramente contingente, vinculada al caso particular, cuando la pérdida de imparcialidad no se vincula a un problema de configuración general del poder del Estado o a problemas generales de diseño institucional, sino que se trata simplemente de situaciones en que hay compromisos ajenos al cumplimiento de la función por parte de quienes tienen deberes públicos desinteresados ligados al acto jurisdiccional en cuestión. Ejemplo: un juez que debe intervenir en un proceso penal, el fiscal que debe perseguir la responsabilidad o los agentes de policía encargados de la investigación están involucrados en el caso mismo o alguien cercano a ellos lo está. En todos estos casos, la implicación personal condiciona la imparcialidad que debe esperarse de los funcionarios involucrados.

Contra lo que puede esperarse, la legislación chilena no dispone de remedios específicamente vinculados a la denegación interesada de justicia. Paradigmática a este respecto es la configuración de la acción de revisión en materia penal en la hipótesis de la letra e) del artículo 473 del Código Procesal Penal: ella solo está configurada de modo tal de paliar los efectos de condenas interesadas, pero no hay regulación precisa de los casos de denegación interesada por sobreseimiento definitivo o absolución condicionada o por ausencia de prosecución condicionada de ese modo.

Por cierto, los distintos remedios jurisdiccionales frente a la inactividad del juez (en el antiguo sistema) o del fiscal (en el actual), o los recursos que el sistema jurídico dispone sean procedentes contra sobreseimientos definitivos y sentencias absolutorias pueden cumplir ese rol. Pero su efecto es por definición limitado y su eficacia puede estar condicionada por las mismas razones que generan la denegación interesada originaria. Esta es la razón por la que en el derecho internacional de los derechos humanos y en la propia experiencia chilena, como veremos, tiende a reaccionarse a denegaciones interesadas de justicia que aunque tengan componentes contingentes, estén vinculadas a problemas generales de diseño transicional.

En lo que sigue, revisaremos tres contextos que han sido fundamentales para la configuración de limitaciones a las reglas de prescripción en casos de denegación interesada de justicia: su desarrollo internacionalmente más famoso en la "superación alemana del pasado"; su configuración en la jurisprudencia de la Corte Interamericana de Justicia; y su evolución en la jurisprudencia de la Corte Suprema.

\subsection{Prescripción y denegación interesada de justicia en el derecho comparado: el caso del derecho alemán}

El antecedente probablemente más conocido se refiere al tratamiento de la jurisprudencia alemana de post-guerra y post-reunificación respecto de los delitos perpetrados por funcionarios del régimen nacional-socialista y de la República Democrática Alemana, respectivamente. En lo que se refiere a la extinción de responsabilidad penal por tiempo a causa de la inactividad del Estado, el derecho alemán conoció dos mecanismos de evitación de impunidad: reconocimiento de suspensiones especiales de la prescripción, por una parte; y ampliaciones retroactivas de plazos de prescripción, por la otra ${ }^{4}$.

En el caso de la aplicación de las reglas de suspensión (Ruhen), la fuente legal parecía ser claramente inaplicable. En efecto, de conformidad con el § 69 del Código Penal Alemán de la

\footnotetext{
${ }^{3}$ Véase nota 16.

${ }^{4}$ La cuestión es, por cierto, algo más compleja, ya que existía una diferencia al menos potencialmente relevante entre las zonas de ocupación de los aliados en la que el Estado ocupante había dictado órdenes de persecución que desconocían explícitamente el efecto de la prescripción y aquellas zonas -en particular la zona francesa y en Berlín - en que no se dictaron instrucciones de esas clases. Precisamente en juicios ligados a la zona francesa es que debió desarrollarse la jurisprudencia de la suspensión de la prescripción.
} 
época (hoy $\S 78 b$ ), la suspensión se aplica durante el tiempo en que exista "un obstáculo legal a la persecución de la responsabilidad penal". Ni en el caso de la Alemania Nazi ni en el caso de la República Democrática Alemana se habían configurado obstáculos de esa clase a la persecución de los delitos cometidos por funcionarios. Lo que hubo, en cambio, fue simple aceptación y conducción estatal a la realización de esos delitos. Se trataba, en ese sentido, de un obstáculo al menos aparentemente fáctico.

Pese a ello, la jurisprudencia encontró una solución creativa en el caso de los delitos cometidos durante la época Nazi: como en las declaraciones del propio ordenamiento jurídico alemán de la época, la voluntad del líder (Führer) era ley, el hecho de que claramente hubiera una voluntad de no persecución en Adolf Hitler habría implicado, jurídicamente, un obstáculo legal a la persecución de la responsabilidad penal de los funcionarios por los crímenes del régimen y, con ello, la aplicabilidad directa de la cláusula de suspensión de la prescripción.

Como es obvio, ese modo de argumentación no funcionaba con la República Democrática Alemana, cuyo ordenamiento jurídico nunca pretendió romper con la exigencia tradicional de que la voluntad popular se expresara a través de mecanismos puramente institucionales. Pese a ello, también la jurisprudencia consideró en general aplicable las cláusulas de suspensión (Ruhen), en una interpretación que terminó siendo aceptada tanto por el Tribunal Supremo Federal Alemán (BGH, el equivalente a nuestra Corte Suprema) como por el Tribunal Constitucional Federal Alemán (BVerfG).

La interpretación en cuestión se desarrolló, en un principio, por analogía con la jurisprudencia relativa a los crímenes cometidos durante el nazismo: si bien no había reconocimiento oficial del carácter legal de la pura voluntad fáctica del partido o de su líder en la República Democrática Alemana, ella sí habría tenido en los hechos la misma fuerza ${ }^{5}$. La "fuerza de ley" de la que en los hechos gozaba la voluntad política dominante sería así el soporte de la aplicabilidad de la cláusula de suspensión de la prescripción. Poco tiempo después, la interpretación en cuestión fue aceptada tanto por el $\mathrm{BGH}^{6}$ como el BVerfG ${ }^{7}$ : las reglas sobre suspensión deben ser aplicadas en situaciones en que la persecución sea impedida por impedimentos cuasi-legales. Eso no quiere decir, por cierto, que toda situación en que puedan comprobarse retardos o inclusos obstáculos a la persecución haga aplicable la suspensión, sino que ella derivarse de una "práctica estatal general que pueda ser catalogada de anti-jurídica".

A diferencia de la jurisprudencia relativa a los crímenes cometidos durante el período nacional-socialista, la línea jurisprudencial vinculada a la República Democrática Alemana es claramente expresiva de desconocimiento de la denegación interesada de justicia y no así de puro desconocimiento de la impunidad en casos de delitos de lesa humanidad ${ }^{8}$. Esto puede verse inmediatamente en el tipo de casos de que se trataba: no solo de casos de homicidio, sino también de delitos de obstrucción a la justicia, prevaricación judicial, coacción y doping. Precisamente por ello, en la dogmática penal alemana ello lleva a una generalización de la tesis del BGH: siempre que pueda verificarse voluntad estatal específica de no persecución, ello hace aplicable las reglas sobre suspensión de la prescripción ${ }^{9}$. Esto es, en los hechos, una aceptación con carácter general praeter legem de la solución que se propone aquí al mismo problema en el derecho chileno: las reglas de suspensión deben interpretarse de modo tal que se impida favorecer el efecto buscado al denegar interesadamente justicia.

La segunda línea jurisprudencial, menos relevante para nuestros efectos, se refiere a la aplicabilidad in actum de plazos extendidos de prescripción respecto de los mismos dos

\footnotetext{
${ }^{5}$ Sentencia del Kammergericht publicada en NStZ 1993, 240. Véase con más detalle ASHOLT (2016), pp. 569 y ss.

${ }^{6}$ BGHSt 40, 48; BGHSt 40, 113; BGH en NJW 1995, 2732.

7 BVerfG en NJW 1998, 2587. Por cierto, en el caso de la sentencia del BVerfG la argumentación tenía por objeto dar cuenta de la constitucionalidad de la así denominada "ley sobre la prescripción" de 1993, cuyo objeto era precisamente "declarar la suspen sión de la prescripción" de los delitos favorecidos por el Estado durante la República Democrática Alemana. El argumento de la aplicabilidad directa de las cláusulas generales de suspensión fue construido con el objeto de dar cuenta del "carácter puram ente declarativo" de la ley: como las reglas generales igual permitían llegar al mismo resultado, la ley no habría cambiado nada relevante. ${ }^{8}$ Sobre la diferencia Infra. 7 y ss.

${ }^{9}$ Así SALIGER (2017), Nm. 15; FISCHER (2015), Nm. 8 y s. Para un listado exhaustivo de referencia, véase ASHOLT (2016), p. 574.
} 
contextos, a saber, crímenes cometidos durante el nazismo y durante la República Democrática Alemana.

El desarrollo de esta línea se retrotrae a las limitaciones que demostró tener desde los años 60 la conjunción del "derecho de ocupación" especialmente instituido después de la derrota de Alemania por los aliados y de la doctrina de la suspensión. De modo sintético: el derecho de ocupación (que en general disponía la inaplicabilidad de la prescripción respecto de ciertos delitos) fue reemplazado ya en 1956 y la pura suspensión durante el tiempo de nopersecución estatal (hasta 1945) hacía que en 1960 (15 años después del fin del régimen) o, en caso de asesinatos, 1965 , todo delito cometido durante la época nazi hubiera prescrito ${ }^{10}$. La dificultad de persecución se generó, de esta forma, tanto por subestimación inicial de la necesidad política de "trabajar el pasado" Nazi como por subestimación de la cantidad de delitos que todavía a esa época no habían sido aclarados.

Con ello, el clima político que se fue instaurando poco a poco a medida que el pasado Nazi se fue abriendo llevó en definitiva a aumentar sustancialmente los plazos de prescripción y a modificar el momento desde el que los plazos debían comenzar a computarse (1960). La modificación progresiva, con aplicación in actum, de los plazos de prescripción fue ratificada por el BVerfG, con el argumento de que la prescripción constituye solo una limitación a la facultad estatal de perseguir delitos y no define, en cambio, al delito mismo, por lo que no se ve protegida por la prohibición constitucional de retroactividad ${ }^{11}$. En términos sustanciales: la prescripción no se encuentra dentro del horizonte de expectativas protegido frente a la modificación ex-post por la prohibición de retroactividad, por lo que el legislador puede establecer la aplicabilidad in actum sin vulnerar las reglas en cuestión.

La segunda línea se refiere, por cierto, a un problema de control de constitucionalidad de legislación y, con ello, cuenta con sus propios mecanismos de control. En ella probablemente se verifica un potencial de expansión mayor - aunque aquí se trataba de casos de denegación interesada de justicia - la jurisprudencia del BVerfG se refiere a la modificación retroactiva de plazos de prescripción y puede ser aplicada con independencia de ese problema. No así en la primera línea jurisprudencial, la que por lo mismo nos interesa directamente. Allí, el problema es la denegación interesada y la solución, la aplicación de las reglas de solución, no es expresiva de una decisión legislativa sino de una interpretación del derecho vigente. Como veremos, el mismo problema se presenta en el derecho chileno.

\subsection{El derecho internacional de los derechos humanos}

El hecho de que la jurisprudencia y la doctrina dominante en Alemania, enfrentadas a problemas de denegación interesada de justicia, sostengan que la prescripción se suspende durante el tiempo que ella dure, no es un antecedente vinculante al desarrollar interpretaciones en el derecho chileno. La referencia al derecho alemán es relevante solo para demostrar la extensión del problema y un modo de razonamiento a su respecto.

Pero para nuestros efectos, es mucho más relevante como cuestión de derecho positivo su tratamiento en la jurisprudencia de la Corte Interamericana de Derechos Humanos y en la Corte Suprema. A continuación, daré cuenta del modo en que la jurisprudencia de ambos tribunales lleva también a concederle efecto a la denegación interesada en limitar la aplicabilidad de defensas de prescripción.

En lo que nos interesa a nosotros, al menos tres líneas jurisprudenciales de la Corte Interamericana de Derechos Humanos tienen relevancia: aquella relativa a las consecuencias favorables a la impunidad de agentes del Estado en el contexto de denegación masiva de justicia durante las dictaduras; aquella relativa específicamente a la justicia militar en las democracias

\footnotetext{
${ }^{10}$ Véase ASHOLT (2016), pp. 351 y ss.

${ }^{11}$ BVerfGE 25, 269.
} 
latinoamericanas y, por último, aquella relativa en particular a las consecuencias de denegación interesada de origen contingente ${ }^{12}$.

\section{a) Amnistía y prescripción en contextos de vulneración estatal de derechos humanos}

La primera línea jurisprudencial es probablemente la más conocida, ya que ha tenido efectos masivos tanto en Chile como en el resto de Latinoamérica. En particular, la Corte ha sostenido de modo continuo la inaplicabilidad de circunstancias liberadoras de responsabilidad penal que favorezcan a los autores de delitos de Estado cometidos en contexto de dictaduras. En dicha línea, la referencia conjunta tanto a la inaplicabilidad de la amnistía como a las reglas de prescripción es ya una frase estándar utilizada por la Corte Interamericana ${ }^{13}$.

Dos son las lógicas que históricamente han convivido en esta línea jurisprudencial: la exclusión del reconocimiento al auto-favorecimiento estatal ${ }^{14}$-en su versión más obvia, por leyes de auto-favorecimiento tales como el Decreto Ley de Amnistía ${ }^{15}$ - por consideración a las garantías de debido proceso y protección judicial (arts. 8 y 25 de la Convención Interamericana de Derechos Humanos) y la afirmación de la inaplicabilidad general de la amnistía y de la prescripción a delitos de lesa humanidad como imposición general de ius cogens en el derecho internacional.

Por cierto, en el contexto de vulneraciones sistemáticas de derechos humanos realizados por dictaduras con control pleno del poder estatal, como tuvo lugar en Chile, las dos lógicas de razonamiento coinciden. La cuestión es, en cambio, distintas en contextos de democracias en transición y ya consolidadas, precisamente a causa de que no necesariamente aquellos casos en que hay voluntades de auto-favorecimiento se refieren a realizaciones sistemáticas de delitos de lesa humanidad y que los delitos más o menos aislados de lesa humanidad que puedan tener lugar no necesariamente pretenden ser ocultados o protegidos por una política general de Estado que busca favorecer a los autores de los delitos en cuestión.

\section{b) Justicia militar en general}

Un segundo ámbito jurisprudencial que tiene incidencia en nuestro contexto se refiere a la competencia de la justicia militar para juzgar delitos cometidos por militares y policías en contra de civiles. En tanto arreglo institucional frecuentemente presente en las democracias transicionales y, en general, en los sistemas jurídicos latinoamericanos, la Corte Interamericana de Derechos Humanos ha producido a su vez una línea jurisprudencial recurrente y consistente a este respecto, de conformidad con la cual la sujeción del conocimiento de delitos que involucren a civiles a la justicia militar es incompatible con las exigencias de imparcialidad e independencia vinculadas a los artículos 8 y 25 de la Convención Interamericana de Derechos Humanos.

La incompatibilidad en cuestión se refiere tanto al caso específico de la sujeción al fuero militar de la persecución de la responsabilidad penal de militares y carabineros por delitos cometidos contra civiles ${ }^{16}$ como al conocimiento por la justicia militar de la persecución de

\footnotetext{
12 En general sobre la jurisprudencia de la Corte Interamericana de Derechos Humanos en relación con la prescripción, véase PARENTI (2010), pp. 211-28. Sobre las excepciones a la prescritptibilidad en el derecho penal con fuente internacional, véase GUZMÁN (2005), pp. 103 y ss.

${ }^{13}$ Véase Corte Interamericana de Derechos Humanos, Barrios Altos v. Perú, de 14 de marzo de 2001, número 41; Trujillo Oroza v. Bolivia, de 27 de febrero de 2002, número 106 (citando Barrios Altos); Almonacid Arellano v. Chile, de 26 de septiembre de 2006, números 112, 151-153.

${ }^{14}$ Así ya BASCUÑÁN (2007), pp. 72 y s. Respecto de la prescripción véase también MAÑALICH (2010), pp. 208 y ss.

${ }^{15}$ Véase a este respecto HORVITZ (2006), p. 222; BASCUÑÁN (2007), pp. 72 y ss.; MAÑALICH (2010), pp. 183y ss.; GUZMÁN (2005), pp. 103y ss.

${ }^{16}$ Corte Interamericana de Derechos Humanos, Durand y Ugarte v. Perú, de 16 de agosto de 2000, números 117-131; Cantoral Benavides v. Perú, de 18 de agosto de 2000, números 111-115; Las Palmeras v. Colombia, de 6 de diciembre de 2001, números 5154; Radilla Pacheco v. México, de 23 de noviembre de 2009, número 272.
} 
responsabilidad por delitos perpetrados por civiles contra carabineros o militares ${ }^{17}$. Esta línea jurisprudencial se encuentra en el origen de la modificación de la competencia de los tribunales militares por la Ley 20.477 y su complementación posterior -técnicamente no demasiado feliz ${ }^{18}$ - por la Ley 20.968 , la que puso fin al problema.

A diferencia de la línea jurisprudencial vinculada a extinción de la responsabilidad penal y crímenes de lesa humanidad, no hay dos clases de razones normativas distintas que la fundamenten. La consideración de incompatibilidad sistemática entre la radicación del conocimiento de causas penales comunes en la justicia militar y las garantías de debido proceso y protección judicial de la Convención se encuentra solo en la falta de imparcialidad de ese arreglo institucional - no hay aquí un problema de delitos de lesa humanidad en sentido estricto-. Se trata así de un reconocimiento a la tendencia sistemática al favorecimiento interesado de militares y policías que produce la sujeción del conocimiento de su responsabilidad penal por delitos comunes a la justicia militar.

\section{c) Denegación interesada de justicia en particular}

Por último, la Corte Interamericana de Derechos Humanos ha reconocido que la inmunización particular frente a la persecución penal también es vulneratoria de las exigencias del debido proceso y de la protección judicial y que ello tiene efectos sobre la exclusión de la responsabilidad penal.

En el caso Bulacio, la formulación del efecto de no favorecimiento por causas de exclusión de la punibilidad en aquello que fueron condicionadas por denegación interesada de justicia es prácticamente explícita ${ }^{19}$. Aquí, se trataba de un caso en que funcionarios policiales habían sido protegidos frente a la posibilidad de persecución penal por el homicidio de un joven. En ese contexto, la Corte consideró que el fraude en la persecución penal hacía inaplicable las reglas de prescripción de la acción penal. La Corte Suprema Argentina confirmó, a su vez, la obligatoriedad del desconocimiento de las reglas de prescripción en el caso ${ }^{20}$.

Por cierto, algunos años después, la Corte pareció haber adoptado un criterio distinto en el caso Albán Cornejo. Aquí se trataba de la persecución de responsabilidad penal en una situación de negligencia médica. Pese a que la Corte dio por establecida una vulneración del Estado de Ecuador a las garantías de debido proceso y protección judicial ${ }^{21}$, explicitó que ello no implicaba que las reglas de prescripción hubieran dejado de ser aplicables ${ }^{22}$.

Para cualquier jurista con conocimiento en el modo de razonamiento necesario a aplicar reglas contenidas en precedentes, la diferencia entre ambos fallos es fácil de explicar: se trata simplemente de reglas distintas, porque el caso en sus aspectos centrales es distinto ("distinguishing"). Esto es: aquello que explica que se haya explicitado el no favorecimiento por prescripción en el caso Bulacio y que, en cambio, la consideración haya sido contraria en el caso Albán, es la diferencia en las condiciones de aplicación de la regla que se vincule a diferencias relevantes entre ambos casos. Así, en el caso Bulacio había una voluntad de auto-favorecimiento de agentes vinculados a la persecución penal sistemáticamente condicionada. En el caso Albán se trataba, en cambio, de negligencia en la persecución penal. Expresado a modo de precedente judicial, ello implica considerar que la aplicabilidad de la prescripción solo debe ser excluida en caso de auto-favorecimiento con implicancias sistemáticas.

\footnotetext{
${ }^{17}$ Central a este respecto Corte Interamericana de Derechos Humanos, Palamara Iribarne v. Chile, de 22 de noviembre de 2005 , número 155

${ }^{18}$ El problema de la nueva redacción del artículo 1ํ de la Ley 20.477 es obvio. La expresión "en ningún caso, los civiles y los menores de edad, que revistan la calidad de víctimas o de imputados, estarán sujetos a la competencia de tribunales militares" es un modo técnicamente poco pulcro de disponer que la competencia para la persecución de la responsabilidad penal de militares por delitos cometidos contra civiles es de la justicia penal ordinaria.

${ }^{19}$ Corte Interamericana de Derechos Humanos, Bulacio v. Argentina, de 18 de septiembre de 2003, número 116.

${ }^{20}$ A este respecto véase solo EIROA (2013), pp. 45 y ss.

${ }^{21}$ Corte Interamericana de Derechos Humanos, Albán Cornejo y otros v. Ecuador, de 22 de noviembre de 2007 , número 109.

${ }^{22}$ Corte Interamericana de Derechos Humanos, Albán Cornejo y otros v. Ecuador, de 22 de noviembre de 2007 , número 111.
} 


\subsection{La jurisprudencia de la Corte Suprema}

Dada la historia política chilena reciente, la Corte Suprema ha debido enfrentarse constantemente el tema de la limitación a la exclusión de la responsabilidad penal en casos de denegación interesada de justicia. La evolución de su jurisprudencia sobre amnistía y prescripción respecto de delitos perpetrados en la dictadura puede ser vista como la reacción de la propia judicatura frente a la realidad de la denegación interesada de justicia que tuvo lugar en Chile. Como veremos, el resultado de esta evolución puede también ser interpretado como una regla de desconocimiento de los efectos beneficiosos aparentes en casos de denegación interesada de justicia con origen sistemático.

La historia es conocida: mientras los primeros casos de derechos humanos fueron en general sobreseídos por la jurisprudencia chilena aplicando precisamente reglas de amnistía ${ }^{23}$, en base al Decreto Ley de Amnistía, y de prescripción, desde los años 2000 la jurisprudencia de la Corte Suprema tuvo un giro que terminó siendo radical. Políticamente considerado, el cambio que tuvo lugar en Chile después de la detención de Pinochet en Londres sin dudas tuvo una influencia relevante. Jurídicamente $-y$ eso es lo relevante aquí- el cambio se produjo en dos o tres estadios, que ciertamente tuvieron algunas oscilaciones ${ }^{24}$ : una primera apertura a la no aplicación de reglas de exclusión de la licitud bajo figuras elusivas como el "secuestro permanente" ${ }^{25}$, un giro mucho más marcado a la exclusión de estas reglas desde el caso Almonacid y su adaptación interna por la Corte Suprema ${ }^{26}$ y luego un período de normalización en que se consideran generalmente inaplicables las reglas sobre prescripción en delitos por violaciones a derechos humanos en Chile ${ }^{27}$, pese a reconocerse en ciertos casos la atenuante especial de media prescripción del artículo 103 del Código Penal ${ }^{28}$.

En la jurisprudencia de la Corte Suprema posterior al caso Almonacid, tres aspectos resultan de primera importancia para nuestros efectos, reflejando una evidente voluntad de combate frente a la impunidad generada por auto-favorecimiento: la reacción de la Corte Suprema a la sentencia de la Corte Interamericana de Derechos Humanos en el caso Almonacid Arellano; la sentencia de la Corte Suprema en el caso los hermanos Toledo; y la reacción de la Corte Suprema al Informe de la Comisión Interamericana de Derechos Humanos en el caso de Alex Lemún.

En el primer caso, tal como ha destacado la propia Corte Interamericana ${ }^{29}$, la Corte Suprema dispuso con fecha 5 de diciembre de 2008 que la justicia penal ordinaria (aquí bajo la forma de un ministro en visita) resultaba competente para conocer del caso Almonacid, que el proceso necesariamente debía haberse reabierto y, finalmente, que el Decreto Ley de Amnistía no podía ser aplicado en el caso en cuestión ${ }^{30}$.

En el caso de los hermanos Toledo, la Corte Suprema no solo dio cuenta de la calificación de los hechos como delitos de lesa humanidad ${ }^{31}$, sino que vinculó la inaplicabilidad de la cosa juzgada, de la amnistía y de la prescripción también al hecho de que la responsabilidad penal

\footnotetext{
${ }^{23}$ Así por ejemplo el caso Corte Suprema, Rol N 5566-1995, de 26 de octubre de 1995 (caso Bárbara Uribe y Edwin van Jurick).

${ }^{24}$ Véase en general GUZMÁN (2013), pp. 153 y ss.; MAÑALICH (2010), pp. 160 y ss.

${ }^{25}$ Así ya en Juzgado de Letras de Lautaro, Rol № 37860, de 20 de septiembre de 1993, confirmado por la sentencia Corte Suprema, de 5 de diciembre de 1995 (caso José Julio Llaullén y Juan Eleuterio Cheuquepán). También Corte Suprema, Rol N $517-2004$, de 17 de noviembre de 2004 (caso Miguel Ángel Sandoval Rodríguez), Corte Suprema, Rol N³452-06, de 10 de mayo de 2007 (caso Londres 38).

${ }^{26}$ Véase Corte Suprema, Rol N 559-2004, de 13 de diciembre de 2006 (caso Hugo Vásquez y Mario Superby). También es relevante, por cierto, la decisión de la Corte Suprema de reabrir el caso Almonacid después del fallo de la Corte Interamericana de Derechos Humanos, disponiendo precisamente su radicación en la justicia penal ordinaria (y no militar). Véase GUZMÁN (2013), pp. 155 y ss. ${ }_{27}$ Claro en Corte Suprema, Rol 3573-2012, de 22 de noviembre de 2012 (caso Grober Venegas Islas), y Rol N 4662-2007, de 30 de septiembre de 2008 (caso Liquiñe).

28 Por ejemplo, Corte Suprema, Rol N 3828-2006, de 30 de julio de 2007 (caso Juan Luis Rivera Matus); Corte Suprema, Rol 46622007, de 30 de septiembre de 2008 (caso Liquiñe).

${ }^{29}$ Resolución de la Corte Interamericana de Derechos Humanos, Almonacid Arellano v. Chile de 18 de noviembre de 2012 , números 6-16.

${ }^{30}$ Así, por ejemplo, Corte Suprema, Rol N 7089-2009; de 4 de agosto de 2010 (caso hermanos Toledo).

${ }^{31}$ Corte Suprema, Rol N 7089-2009; de 4 de agosto de 2010 (caso hermanos Toledo), considerandos primero a tercero.
} 
correspondiente no hubiera sido perseguida con seriedad. Literalmente: "constituye una violación de una obligación de este carácter (obligación de investigar y perseguir la responsabilidad penal) permitir el efecto de la cosa juzgada o de la prescripción derivada de la realización de un simulacro de investigación, o de una que ha sido deficiente o, incluso, realizada por un tribunal de fuero que no ofrece garantías sobre la imparcialidad del juzgamiento" ${ }^{32}$.

El último estadio viene constituido por la reacción de la Corte Suprema frente al caso de Alex Lemún -aquel en que precisamente tuvo su origen la investigación vinculada a este artículo-. En el caso en cuestión ${ }^{33}$, un grupo de carabineros dio muerte a la víctima, por medio de disparos con armas de fuego, en el contexto de la represión de la ocupación de un terreno por comuneros mapuches durante el año 2002.

La justicia militar asumió la investigación de los hechos y, a la larga, bloqueó cualquier posibilidad de persecución, decretando el sobreseimiento temporal y la suspensión del procedimiento "por no resultar completamente justificada la perpetración del delito que hubiera dado motivo a la formación del sumario" (artículo 409 Código de Procedimiento Penal) el año $2004^{34}$. Al ver bloqueada la posibilidad de perseguir responsabilidad penal por la muerte de su hijo, la familia denunció el 2006 los hechos a la Comisión Interamericana de Derechos Humanos, la admitió el 2012 la causa a tramitación y evacuó su informe el 21 de marzo de 2017.

En su informe, la Comisión concluyó que el Estado de Chile era responsable por una serie de violaciones a los derechos humanos vinculados al caso, incluyendo una vulneración a la debida protección judicial de sus garantías producto de la denegación de justicia que su familia había sufrido sistemáticamente ${ }^{35}$. Para subsanar las violaciones de derechos humanos, la Comisión recomendó, entre otras cosas, "iniciar una investigación efectiva y dentro de un plazo razonable con el objeto de imponer las sanciones que correspondan por las violaciones de derechos humanos" verificadas en el proceso ${ }^{36}$.

Frente a ello, el 2 de octubre de 2017, el pleno de la Corte Suprema dejó sin efecto el sobreseimiento temporal dictado el año 2004 e instruyó al Tercer Juzgado Militar de Valdivia que, en virtud de lo dispuesto en el artículo $1^{\circ}$ de la Ley 20.477 modificado por la Ley 20.968, remitiera los antecedentes en cuestión a la autoridad del sistema de justicia penal ordinario competente para perseguir la responsabilidad penal de los hechos, a saber, la Fiscalía Local de Angol $^{37}$. La causa se encuentra desde entonces radicada en la justicia penal común, la que confirmó explícitamente la inaplicabilidad del sobreseimiento definitivo por prescripción ${ }^{38}$.

Todo lo anterior permite concluir que, en su evolución actual, el sistema judicial chileno -informado por el sistema interamericano de derechos humanos - establece que el efecto de prescripción en situaciones de denegación interesada de justicia con un origen sistemática debe ser desconocido.

\section{Las reglas de prescripción en el derecho penal chileno en situaciones de denegación interesada de justicia}

Pese a que el desconocimiento del favorecimiento por la prescripción en casos de denegación interesada de justicia se encuentra reconocido por la Corte Interamericana de Derechos Humanos, por la Comisión y por la Corte Suprema, en todos estos casos se trata de declaraciones de efectos que no pueden ser aceptados - que haya impunidad por causa de prescripción- sin que haya una configuración precisa del modo en que se produce jurídicamente ese efecto en el derecho chileno.

\footnotetext{
${ }^{32}$ Corte Suprema, Rol N 7089-2009; de 4 de agosto de 2010 (caso hermanos Toledo), considerando séptimo.

${ }^{33}$ Cuarto Juzgado Militar de Valdivia, Rol N²33-2002.

${ }^{34}$ Cuarto Juzgado Militar de Valdivia, Rol N²33-2002, fs. 1191.

${ }^{35}$ Comisión Interamericana de Derechos Humanos, Informe 31/17 en el caso Lemún y otros v. Chile, de 21 de marzo de 2017.

${ }^{36}$ Comisión Interamericana de Derechos Humanos, Informe 31/17 en el caso Lemún y otros v. Chile, de 21 de marzo de 2017.

${ }^{37}$ Cuarto Juzgado Militar de Valdivia, Rol N²33-2002, Fs. 1272. La individualización propia de la causa en la Corte Suprema es causa administrativa AD-1488-2017.

38 Juzgado de Garantía de Angol, RUC № 1701008346-K, de 3 de mayo de 2019.
} 
En esta sección, me interesa responder a esta pregunta. Para ello, en primer lugar, explicaré las reglas que podrían permitir, aparentemente, reconocer una defensa de prescripción en los casos que nos interesan (1). La subsección (2) da cuenta de las alternativas interpretativas que permiten justificar un desconocimiento de ese efecto.

\subsection{Las reglas de prescripción en contextos de denegación interesada de justicia}

El sistema normativo que lleva al reconocimiento, o no, de un efecto de prescripción en situaciones de denegación interesada de justicia es sencillo de entender. De conformidad con el artículo 94 del Código Penal (CP), la acción penal prescribe en 10 años cuando se trata de la persecución de un crimen y en 5 años cuando se trata de la persecución de un simple delito.

De conformidad con el artículo $95 \mathrm{CP}$, la prescripción empieza a correr el día en que se perpetra el delito. Pese a que la doctrina discute si ello se corresponde con el momento de la acción, del resultado u otro ${ }^{39}$, ninguna interpretación tiene un efecto inherente que permita limitar el efecto de favorecimiento de la denegación interesada.

Más relevante para estos efectos son las reglas de suspensión ${ }^{40}$. Dependiendo de si, en algún momento, se dirige la acción penal en contra de los implicados, el artículo 96 CP dispone la suspensión del transcurso del tiempo de la prescripción ${ }^{41}$. Ello permite así distinguir dos situaciones relevantes: casos en que la denegación interesada de justicia tiene lugar sin intervención alguna del aparato judicial - por lo que nunca se produjo un efecto de suspensión- y casos en que el efecto de suspensión se produjo al menos inicialmente.

Las razones por las que en el primer caso puede producirse un efecto de favorecimiento son obvias: como no se suspende nunca el transcurso de la prescripción, basta que se cumpla el plazo para que pueda aparentemente plantearse una excepción de prescripción. Pero también en la segunda hipótesis tienden a producirse problemas por aplicación de la parte final del artículo 96 CP. Conforme a este, si la prosecución del proceso se paraliza por tres años, el efecto de la suspensión termina y el cómputo de la prescripción de la acción penal corre como si nunca se hubiera suspendido ${ }^{42}$. Exactamente qué quiere decir que se "paralice la prosecución por tres años" es algo que ha sido debatido históricamente en Chile en casos normales ${ }^{43}$. Procesalmente, ello se expresa con mayor claridad en los casos en que se dispone el sobreseimiento temporal de conformidad con el artículo 252 CPP y en los casos en que se comunica una decisión de no perseverar (art. 248 c) CPP).

La pregunta relevante es, por ello, por el reconocimiento de un efecto de suspensión en casos en que o bien no haya persecución penal formal alguna por denegación interesada de justicia y casos en los cuales, si bien se produjo inicialmente un efecto de suspensión, este terminó por aplicación de la parte final del artículo 96 CP. De este modo, hay dos situaciones jurídicas distintas que nos interesa revisar: casos en que hay denegación ab initio por completa

\footnotetext{
39 GUZMÁN (2002), pp. 469 y ss.; MERA (2011a), p. 726; CURY (2009), p. 801; GARRIDO (1997), pp. 390 y ss.; NOVOA (1966), pp. 452 y ss.

${ }^{40}$ Así también GUZMÁN (2005), pp. 103 y ss., argumentando contra la solución de los problemas de denegación interesada por vía de establecimiento de imprescriptibilidad y a favor de soluciones interpretativas en ámbitos tales como las reglas de suspensión. ${ }^{41}$ En oposición al derecho civil y a la regulación penal comparada en otros ordenamientos jurídicos, el CP trata a la injerencia de una pretensión manifestada en un procedimiento como un caso de "suspensión" (el plazo simplemente no corre) y no así de “interrupción” (el plazo empieza a correr de nuevo). La lógica de la suspensión que se encuentra contenida en el Código Civil -la prescripción se suspende en la medida en que hay obstáculos legales al ejercicio de la acción, por ejemplo por incapacidad del titular - no es así reconocida en el CP chileno-.

42 En algo que es unánimemente reconocido por la doctrina nacional, el CP habla erradamente de interrupción en este punto: el plazo corre como si nunca se hubiera “interrumpido". Véase solo LABATUT (1979), p. 330; NOVOA (1966), p. 456; CURY (2009), p. 802.

43 Profusamente NOVOA (1966), p. 456, citando jurisprudencia histórica a favor y en contra de la aplicación del término de la suspensión cuando la paralización tiene su origen en desidia judicial. En ninguno de los casos se trata de un problema de protección estatal de funcionarios, sino de pérdidas de expediente o congelamiento del proceso antes de la vista de la causa en las cortes. En casos de esta clase, la doctrina en general considera que se trata de "paralizaciones" para efectos del artículo 96 CP. Así LABATUT (1979), p. 331; CURY (2009), p. 802; GARRIDO 1997), p. 396; MERA (2011b), p. 728; GUZMÁN (2003), p. 476.
} 
inactividad; y casos en que hay paralización que produce interrupción de la suspensión. Esta es una primera distinción relevante para entender los distintos supuestos que nos interesante.

Una segunda variable relevante dice relación con el procesamiento institucional de la denegación interesada de justicia. En la práctica, no es inusual que, frente a situaciones de consolidadas a nivel interno, los afectados reclamen a organismos internacionales. Como los problemas que se presentan en uno y otro caso son distintos, esta es una segunda distinción relevante. La Tabla 1 refleja la sistematización que se sigue del cruce de estas dos distinciones.

Tabla 1: Sistematización de casos relevantes

\begin{tabular}{|l|c|c|}
\hline & Paralización sobreviniente & Inactividad inicial \\
\hline Con reclamo internacional & 1 & 2 \\
\hline Sin reclamo internacional & 3 & 4 \\
\hline
\end{tabular}

A continuación, daré cuenta del modo en que jurídicamente puede formalizarse el reconocimiento de un defecto de desconocimiento de la prescripción en cada uno de los casos relevantes.

\subsection{Suspensión y término de la suspensión en casos de denegación interesada de justicia}

La primera situación que nos interesa revisar se refiere, de este modo, a casos en que, si bien se produjo un efecto inicial de suspensión de la prescripción de la acción penal, ella se vio interrumpida posteriormente como consecuencia de acciones de denegación interesada de justicia. Como hemos visto, el artículo 96 parte final CP establece el término de la suspensión en caso de que el procedimiento termine sin condena o en caso de que su prosecución se paralice por 3 años.

En situaciones de denegación interesada de justicia sistemáticamente condicionada casos en que, como vimos, el sistema dispone desconocer posibles efectos de prescripciónhay dos vías alternativas que permiten desconocer el efecto de interrupción de la suspensión en estos casos.

La primera vía argumentativa se vincula a los casos en que la paralización de la persecución es contestada con reclamos internacionales de derechos humanos. En la Tabla 1, este es el caso 1. Como en este caso por definición hay declaración institucional posterior de si se produjo, o no, denegación interesada de justicia, se trata del supuesto menos riesgoso institucionalmente en el desconocimiento de efectos de prescripción. Aquí, para proveer el efecto ordenado por la propia Corte o Comisión de desconocer posibles defensas de prescripción, basta interpretar la parte final del artículo $96 \mathrm{CP}$ de modo tal de no considerar paralizada la prosecución del proceso penal cuando media todavía un reclamo (posteriormente exitoso) de derechos humanos que manifieste una pretensión punitiva al reclamar por impunidad

Una interpretación de este caso es plausible e institucionalmente sana por el efecto que, como veremos, tiene la declaración de impunidad estatalmente favorecida en el sistema interamericano de derechos humanos: también en Chile, ella en general lleva a la inaplicabilidad de causales de exclusión de la punibilidad. De este modo, al tratarse ante todo de una denuncia cuyo objeto era detener un arreglo de impunidad generado por los propios organismos del Estado que habían asumido competencia sobre el caso, la continuación de un proceso ante la Comisión o ante la Corte Interamericana debe considerarse un antecedente suficiente para no tener por configurado el supuesto del artículo 96 parte final CP de "paralización de la prosecución (del procedimiento penal)", en la medida en que el reclamo sea exitoso.

Lo anterior no quiere decir, por cierto, que toda vulneración de derechos humanos por el Estado a causa de infracción de obligaciones de castigo haga inaplicable las reglas de prescripción. Solo si el reclamo manifiesta en sí mismo una pretensión de remedio de la falta de 
voluntad de perseguir la responsabilidad penal y ello es confirmado, ex post, por la Comisión o por la Corte Interamericana, entonces la prosecución del proceso de castigo no se paralizó para efectos jurídicos.

El mismo razonamiento es aplicable a los casos en que hay denegación por inactividad o protección desde un inicio y ello es alegado y declarado por los organismos internacionales -el caso 3-. Aquí, por cierto, el efecto de desconocimiento de la prescripción no puede producirse por reducción teleológica de la parte final del artículo $96 \mathrm{CP}$, ya que simplemente nunca empezó a producirse un efecto de suspensión. Antes, aquí se trata de una ampliación teleológica de la regla de la segunda frase del siguiente tipo: "y se suspende desde que el procedimiento se dirige contra él o en la medida en que haya una voluntad sistemática e irresistible del propio aparato estatal de favorecer su impunidad"44. Como hemos visto, este es el estándar mínimo con el que de facto operan los organismos internacionales de derechos humanos. Como el control de la aplicabilidad de esta cláusula está entregado a un sistema institucional especial, el reconocimiento de este efecto no debiera ser especialmente riesgoso.

Los casos más problemáticos son, de este modo, los casos 2 y 4 . Aquí por definición no hay denuncia internacional y, por lo mismo, declaración institucional especial de la denegación interesada de justicia. Aunque hay antecedentes doctrinales de derecho comparado que reconocen un efecto general de reducción teleológica en estos $\operatorname{casos}^{45}$, reconocer el mismo efecto en estos casos tiene un potencial de deformación institucional relevante. Como en la evolución actual, el desconocimiento de las defensas de exención de responsabilidad penal ligadas a la denegación interesada de justicia se limita a casos con un origen sistemático, es institucionalmente razonable que se exija una declaración de ese origen por condenas de derechos humanos. Ello refuerza la relevancia del sistema interamericano de derechos humanos y tiende a darle una función institucional específica, evitando al mismo tiempo el riesgo de control judicial de instancia de problemas que son sistemáticos. No quiero con esto sostener que ello sea razonable en todos los casos, ante todo porque no alcanzo a ver el abanico de casos que pueden presentarse. Pero sí es crucial mantener a la vista que el criterio central de control está dado por la supervigilancia de tribunales superiores (por recursos domésticos) y de los organismos internacionales de derechos humanos.

\section{Conclusiones}

En su evolución actual, el sistema judicial chileno dispone inequívocamente el desconocimiento de reglas que favorezcan la denegación interesada de justicia. Esa disposición alcanza también a los casos que no tienen su origen en contextos dictatoriales, sino en arreglos o prácticas institucionales deficientes que favorecen sistemáticamente la impunidad de agentes del Estado vinculados a las mismas instituciones encargadas de la persecución penal. Cuando la inactividad absoluta en la persecución penal, o su paralización subsecuente, tienen un origen sistemático de esta clase, la jurisprudencia internacional obliga a considerar que el transcurso de la prescripción se suspendió (o no se interrumpió la suspensión) mientras duró la denegación en cuestión.

Inequívocamente, ese efecto debe reconocerse en casos en que haya denuncia de la denegación ante los organismos domésticos y posteriormente internacionales, y ello sea así declarado. En estos casos, basta con considerar que durante la tramitación de la denuncia y durante el período de implementación de sus efectos debe considerarse suspendida la prescripción. La situación más problemática se produce, en cambio, en los casos en que no hay denuncia, sino que la defensa de prescripción (y la discusión respecto a si hubo suspensión) se presenta sin su intermediación. Aquí, formalmente se puede alegar à la alemana que hay una situación especial de suspensión más allá de lo provisto por el artículo 96 CP. Pero reconocer de

\footnotetext{
${ }^{44}$ Similar, en general, GUZMÁN (2005).

${ }^{45}$ Véase nota 9 respecto del derecho alemán.
} 
modo general este argumento puede tener efectos institucionales perniciosos, entre otros por debilitar al sistema interamericano de derechos humanos. Por ello, al menos debe considerarse que el caso normal solo se refiere a las hipótesis en que intermedia un reclamo de esta clase.

\section{BIBLIOGRAFÍA CITADA}

ASHOLT, MARTIN (2016): Verjährung im Strafrecht (Tübingen, Mohr Siebeck).

BASCUÑÁN, ANTONIO (2007): "Derechos fundamentales y derecho penal”, en: Revista de Estudios de la Justicia (Vol. 9), pp. 47-74.

CURY, ENRIQUE (2009): Derecho Penal Parte General, 9a edición (Santiago, Ediciones Universidad Católica de Chile).

EIROA, PABLO (2013): "La eficacia de las decisiones de los órganos interamericanos de protección de los derechos humanos en Argentina", en: Ambos, Kai; Malarino, Ezequiel y Steiner, Christian (Eds.), Sistema interamericano de protección de los derechos humanos y derecho penal internacional (Bogotá, Fundación Konrad Adenauer), tomo III, pp. 25-52.

FISCHER, THOMAS (2015): “§ 78b”, en: Fischer, Thomas, Strafgesetzbuch Kommentar, 62a edición (München, C.H. Beck).

GARRIDO, MARIO (1997): Derecho Penal Parte General, 2aa edición (Santiago, Editorial Jurídica), tomo I.

GUZMÁN, JOSÉ LUIS (2002): "De la extinción de la responsabilidad penal”, en: Politoff, Sergio y Ortiz, Luis, Texto comentado del Código Penal (Santiago, Editorial Jurídica), pp. 433-487.

(2005): “Crímenes internacionales y prescripción", en: Ambos, Kai; Malarino, Ezequiel y Woischnik, Jan (Eds.), Temas actuales de Derecho penal internacional. Contribuciones de América Latina, Alemania y España (Montevideo, Konrad-Adenauer-Stiftung), pp. 103-115.

(2013): "El caso de Chile", en: Ambos, Kai; Malarino, Ezequiel y Steiner, Christian (Eds.), Sistema interamericano de protección de los derechos humanos y derecho penal internacional (Bogotá, Fundación Konrad Adenauer), tomo III, pp. 135-164.

HORVITZ, MARía INÉS (2006): “Amnistía y prescripción en causas sobre violación de derechos humanos en Chile", en: Anuario de Derechos Humanos (2006), pp. 217-225.

LABATUt, Gustavo (1979): Derecho Penal, 8a edición (Santiago, Editorial Jurídica), tomo I.

MAÑALICH, JUAN PABLO (2010): Terror, pena y amnistía (Santiago, Flandes Indiano).

Mera, JoRge (2011A): “Artículo 95”, en: Couso, Jaime y Hernández, Héctor (Dirs.), Código Penal Comentado. Parte General (Santiago, Thomson Reuters), pp. 725-727.

(2011B): “Artículo 96", en: Couso, Jaime y Hernández, Héctor (Dirs.), Código Penal Comentado. Parte General (Santiago, Thomson Reuters), pp. 728-730.

NovoA, EduARDo (1966): Curso de Derecho Penal Chileno (Santiago, Editorial Jurídica), tomo II.

PARENTI, PABlo (2010): "La inaplicabilidad de normas sobre prescripción en la jurisprudencia de la Corte Interamericana de Derechos Humanos", en: Elsner, Gisela (Ed.), Sistema Interamericano de Protección de los Derechos Humanos y Derecho Penal Internacional (Montevideo, Fundación Konrad Adenauer), tomo I, pp. 211-228.

SAliger, Frank (2017): “§ 78b”, en: Kindhäuser, Urs; Neumann, Ulfrid y Paeffgen, Hans-Ulrich, Nomos Kommentar Strafgesetzbuch, 5a edición (Baden-Baden, Nomos). 


\section{JURISPRUDENCIA CITADA}

BVERFGE 25, 269 (1969).

KAMMERGERICHT EN NEUE ZeITSCHRIFT FÜR StRAFRECHT 1993, 240 (1993).

CONTRA MARIO PonCE ORELLANA Y OtRos (1993): Juzgado de Letras de Lautaro 20 septiembre 1993 (procedimiento ordinario penal), Rol № 37860 (caso José Julio Llaullén y Juan Eleuterio Cheuquepán). Sentencia confirmada Corte Suprema 5 de diciembre de 1995.

BGHST 40, 48 (1994).

BGHST 40, 113 (1994).

BGH EN NEUE JURISTISCHE WOCHENSCHRIFT 1995, 2732 (1995).

Contra Osvaldo Romo Mena (1995): Corte Suprema 26 octubre 1995 (recurso de queja), Rol № 5566-1995 (caso Bárbara Uribe y Edwin van Jurick).

BVERFG EN NEUE JURISTISCHE WOCHENSCHRIFT 1998, 2587 (1998).

DuRANd y Ugarte V. Perú (2000): Corte Interamericana de Derechos Humanos 16 de agosto de 2000 (sentencia de fondo).

Cantoral Benavides v. Perú (2000): Corte Interamericana de Derechos Humanos 18 de agosto de 2000 (sentencia de fondo).

Barrios Altos V. Perú (2001): Corte Interamericana de Derechos Humanos 14 de marzo de 2001 (sentencia de Fondo).

LAS PALMERAS V. Colombia (2001): Corte Interamericana de Derechos Humanos 6 de diciembre de 2001 (sentencia de fondo).

Trujillo Oroza V. Bolivia (2002): Corte Interamericana de Derechos Humanos 27 de febrero de 2002 (sentencia de reparaciones y costas).

CONTRA JUAN CONTRERAS SEPÚLVEDA Y OTROS (2004): Corte Suprema 17 noviembre 2004 (casación fondo y forma), Rol № 517-2004 (caso Miguel Ángel Sandoval Rodríguez).

CARPIO Nicolle y OtRos v. Guatemala (2004): Corte Interamericana de Derechos Humanos 22 de noviembre de 2004 (sentencia de fondo, reparaciones y costas).

Palamara Iribarne v. Chile (2005): Corte Interamericana de Derechos Humanos 22 de noviembre de 2005 (sentencia de fondo, reparaciones y costas).

Almonacid Arellano v. Chile (2006): Corte Interamericana de Derechos Humanos 26 de septiembre de 2006 (sentencia de excepciones preliminares, fondos, reparaciones y costas).

CONTRA PAULINO FloRES Y OTRO (2006): Corte Suprema 13 diciembre 2006 (casación fondo), Rol № 559-2004 (caso Hugo Vásquez y Mario Superby).

CONTRA BASCLAy ZaPATA y ENRIQUe Romo Mena (2007): Corte Suprema 10 mayo 2007 (casación fondo), Rol № 3452-06 (Caso Londres 38).

CONTRA FREDDY RUIZ BUNGER Y OtROS (2007): Corte Suprema 30 julio 2007 (casación fondo y forma), Rol № 3808-2006 (caso Juan Luis Rivera Matus).

AlBÁN CORNEJO Y OtROS V. ECUADOR (2007): Corte Interamericana de Derechos Humanos 22 de noviembre de 2007 (sentencia de fondo, reparaciones y costas).

CONTRA LUIS GARCíA GUZMÁN Y OTROS (2008): Corte Suprema 30 septiembre 2008 (casación fondo y forma), rol 4662-2007 (caso Liquiñe). 
RADILLA PACHECO V. MÉXICO (2009): Corte Interamericana de Derechos Humanos 23 de noviembre de 2009 (sentencia de resolución de excepciones preliminares, fondo, reparaciones y costas).

Contra AleX Vicent Ambler Hinojosa y otros (2010): Corte Suprema sentencia de reemplazo de 4 agosto 2010 (casación fondo), Rol № 7089-2009 (caso Hermanos Toledo).

Almonacid Arellano v. Chile (2010): Corte Interamericana de Derechos Humanos 18 de noviembre de 2010 (supervisión de cumplimiento de la sentencia).

Contra PatRicio Padilla Villen y otros (2012): Corte Suprema 22 noviembre 2012 (casación fondo), Rol № 3573-2012 (caso Grober Venegas Islas).

Lemún Y OtRos V. ChILE (2017): Comisión Interamericana de Derechos Humanos 21 de marzo de 2017 (Informe 31/17).

AUTO ACORDADO 1488-2017 (2017): Corte Suprema 2 octubre 2017 (caso Alex Lemún). 